\title{
Web Analytics for Each Stage of E-government Implementation: A Study in the Indian Context
}

\author{
Rakhi Tripathi \\ Centre for Digital Innovation, FORE School of Management, New Delhi, India \\ Correspondence should be addressed to: Rakhi Tripathi; rakhitripathi@gmail.com \\ Received date: 10 November 2016; Accepted date: 15 November 2016; \\ Published date: 17 January 2017 \\ Academic Editor: Zaigham Mahmood
}

Copyright (C) 2017. Rakhi Tripathi. Distributed under Creative Commons CC-BY 4.0

\begin{abstract}
More than twenty stage, or maturity, e-government models have been suggested in the last fifteen years, globally. The number of stages varies from model to model, but overall there is general consensus on five generic stages of e-government maturity, identified as: information; interaction; transaction; integration and one-stop portal for e-government. In India, as e-government services are being provisioned and consumed by the stakeholders including general public, a significant number of government bodies are at information, interaction and transaction stages of the generic growth model. Some government departments and ministries are gradually moving towards integration (horizontally and vertically) but none of the government organizations in India is at the full interoperable stage. The interface between the citizens and e-government services is through portals. An intuitive and easy user interface is crucial for each stage of e-government maturity so that citizens can fully utilize e-government services. Availability of the relevant technology to the general public is also imperative. It is noticeable that with the rise in online interaction and shift from Web 2.0 to Web 3.0, the use of e-government services has increased considerably. Keeping the stages of e-government growth model in mind, it is highly important that the response of the citizens and other stakeholders is measured and analysed at each level, mainly to understand the effectiveness of the provision. Therefore, web analytics at each stage of e-government is crucial. The objective of the paper is to identify the key performance indicators for each level of e-government growth and suggest relevant web analytic tools that can help in analyzing the response of citizens and to further help in improving the e-government process.
\end{abstract}

Keywords: Maturity models, E-government, Transaction, Integration, Web Analytics, Web 2.0, Web 3.0, Key performance indicators

Cite this Article as: Rakhi Tripathi (2017)," Web Analytics for Each Stage of E-government Implementation: A Study in the Indian Context", Journal of e-Government Studies and Best Practices, Vol. 2017 (2017), Article ID 295851, DOI:10.5171/2017.295851 


\section{Introduction}

India is deploying e-governance solutions to provide online public services to citizens and the business sector. Some of the online services include online bill payment, taxes, land records, income certificates, loans, driving licenses, birth and death certificates and other government entitlement programs. The objective is to provide a single window access to the information and services where the backend is interoperable.

Over the years a number of e-government stage models have been developed to estimate the growth of e-government (Baum and Di Maio, 2000; Deloitte, 2001; Hiller and Be'langer, 2001; Layne and Lee, 2001; Moon, 2002; Ronaghan, 2001; United Nations \& American Society for Public Administration, 2002, Chen et al. 2011; Kim and Grant, 2010; Alhomod 2012). All these e-government maturity models have suggested four to six stages starting from providing basic information to an interoperable level which is also quoted as one stop government portal. Tripathi et al argued in 2014 that all these stages might not be in the same order. For example, there are certain government portals that have the objective of only providing information to the citizens. The nature of such portals is not to offer transactional services to the citizens. But these portals further need to be integrated both vertically and horizontally for a larger view. Hence, the transaction level is skipped. Another reason for not including the transaction level in the development of the Government portals is security (Schuppan, 2009). Due to potential threats from cyber attacks and misuse of crucial information, interaction and transactions are not included in the portal of certain departments of Government. However, the portal of such departments is integrated with all its departments. Moreover, these portals need to be integrated horizontally with other departments of the Government.

Every department of Government in India, which is moving towards e-government, has a web presence. With Internet moving towards web 4.0 and more devices such as tablets and cell phones coming up and with mobile apps and mobile websites, citizen interaction has become a key objective. With this power of interaction citizens are able to give feedback, ask query, fill online forms, file income tax online etc.

Government organizations, along with achieving higher levels of e-government, must also analyse the performance of their portal and understand citizens' response. With the objective of analyzing the performance of Government departments present at different stages of growth models, this paper focuses on the following research questions:

- What are the objectives of Government organizations in India at each stage of e-government model?

- What are the key performance indicators for each stage of Government portals in the Indian context?

- Which are the most widely used web analytic tools that can be used to measure the performance of Government portals at different stages?

For this paper, the readers may note that even though e-government has moved to egovernment 2.0, still in India there are several Government departments that are new to e-government. These departments are yet to achieve any of the growth stages. Therefore, the stage models are still relevant in the Indian context.

\section{Literature Review}

In 2001, Layne and Lee developed a stage model for the portal development for Government organization. According to them the primary objective of Government portal is to achieve an integrated level where all the functions are integrated. For the next one decade different stage models from all over the world evolved (Deloitte, 2001; Hiller and Belanger, 2001; Moon, 2002; Ronaghan, 2001; Pena-lopez, 2012, Shahkooh et al. 2008; Chen et al. 2011; Kim and Grant, 2010; Alhomod 2012). All the developed maturity models present large similarities (Fath-Allah, 2014). Fath-Allah (2014) added that models focus on the evo- 
lution of e-government using sequential steps, for instance from immature to mature e-government with improved quality. From an academic perspective, the most famous maturity models are - for example the Layne and Lee 2001 model and the Andersen and Henriksen (2006) model. The maturity models offer a way to rank egovernment portals and guide agencies to enhance their portals' quality. All these models predict the linear, stepwise, and progressive development of e-government. Governments begin with a fairly basic, in some cases even primitive, Web presence. They pass through predictable stages of egovernment, such as interactivity, transactions, and integration, and then arrive at an e-government nirvana. This final step is described variously as either the seamless delivery of governmental information and services, e-participation, e-democracy, governmental transformation, or some combination of the above. The models do not, however, tell us how this progression or evolution will occur or how long it will take to fully unfold.

Apart from being developed, the egovernment stage models have been analyzed by various authors over the years (Siau and Long, 2005; Lee, 2010; Almarabeh and AbuAli, 2010). According to Coursey and Norris (2008), these models are partly descriptive, partly predictive and partly normative. Based on a systematic comparison of stage models of egovernment currently available in the literature, a common frame of reference for e-government development has been developed by Lee (2010). This frame of reference consists of five metaphorical stages: presenting, assimilating, reforming, morphing and e-governance which can be decomposed into two themes (citizen/service and operation/technology) with nine elementary concepts (information, interaction, integration, transaction, streamlining, participation, transformation, involvement and, process management). Analyzed by Zarei et. al., (2008) in Iran, it seems these models are more appropriate for developed countries that have up-to-date technology, and more non-technical issues such as concentration on public awareness and e-readiness. Motivations toward e- government implementation are essentially different in developing countries. Moreover, according to Yildiz (2007), such models may not be applicable to egovernment development in developing countries, as those countries have a chance to learn from the e-government successes and failures of developed countries. It may be argued that developing countries have a much faster learning curve; they can perform the requirements of all the stages almost simultaneously. Fath-Allah et al. (2015) compared 25 e-government maturity models and highlighted 4 main issues related to the e-government maturity models: stage names; stage numbers year and country, stage objectives and stage features. Tripathi et al (2014) analyzed different stage models and came up with five stages of portal suitable in the Indian context: information, interaction, transaction, integration and one-stop portal. At "Information" stage, the website provides information about the organization (Buccoliero and Bellio, 2010). This stage varies from basic information to elaborated information provided on website. "Interaction" (Sandoval-Almazan et al., 2010) stage involves online form submission, queries and correspondence, etc. Even this stage has range. Services like catalogues, accept payments and supplies are provided at "Transaction" stage (Ntaliani et al., 2009). Organizations are moving from informational website to interactive website where it allows anyone to create and share information online - a space for collaboration, conversation, and interaction; a space that is highly dynamic, flexible, and adaptable. This according to Coombs (2007) is Web 2.0.

According to the official definition of Web Analytics Association (2008), web analytics refers to a combination of (a) measuring, (b) acquisition, (c) analyzing and (d) reporting of data collected from the Internet with the aim of understanding and optimizing web experience. Understanding of the web and website optimization provides a more adapted approach to a target audience with the goal of increasing conversion rates (Waisberg \& Kaushik, 2009), as well as customer loyalty. According to Bekavac and Praničević (2015), web analytics is the 
analysis of qualitative and quantitative data on the website in order to continuously improve the online experience of visitors, which leads to more efficient and effective realization of the company's planned goals. Quantitative data provide insight into visitor behaviour such as the previous web page prior to reaching the actual website. In addition, the acquisition of qualitative data provides answers as to why visitors behave in a certain way. Continuous improvement of online users based on information obtained in web analytics is a key aspect of the web analytics concept.

Waisberg \& Kaushik (2009) identified the following steps in a web analytics process: Objective (goal) determination; KPIs definition; Data collection; Data analysis; Change implementation. The objectives of a website vary from one organization to another. Hence, there is no single answer. Measuring the success of objectives is accomplished by defining key performance indicators (KPIs) that show the particular progress or detect lagging in achieving goals. Each KPI is expected to correlate with a specific action and match the criteria/attributes of timelessness, simplicity, relevance and usefulness. It is recommended that a defined KPI has to be promptly available (timelessness), simple for decision maker to understand (simple), as well as relevant (relevance) and useful (usefulness) to the specific company (Dave and Patron, 2012; Waisberg \& Kaushik, 2009).

\section{Research Methodology}

Exploratory qualitative research from peer review literature approach has been used. Tripathi et al (2014) analyzed different stage models and came up with five stages of e-government portal suitable in the Indian context: information, interaction, transaction, integration and one-stop portal. As examined by Tripathi et al (2014), India has not yet reached the one-stop portal stage. Hence, this paper will cover the first four stages with the following objectives:
- Identifying the objectives of Government portal at each stage of egovernment growth model.

- Defining Key Performance Indicators (KPIs) at each stage of egovernment maturity models.

- Suggesting Web Analytic tools at each stage of e-government portal to analyze the KPIs.

\section{Stages of e-Government Maturity Mod- els and Web Analytics: The Indian Con- text}

This section visits each e-government maturity stage and identifies its objectives along with key performance indicators. Once the KPIs are identified, web analytic tools are suggested. As already mentioned above, the final stage of one-stop portal has been excluded in this paper as it has not been fully approached in the Indian context.

\section{Stage I: Information}

This stage is also called Catalogue (Layne and Lee, 2001), Presence on Web (Kim and Grant, 2010 and Alhomod et al. 2012), Online presence (Shahkooh et al., 2008) and Emerging information services (Penalopez, 2012). The first stage is mainly concerned with "presence on the Web". Each Government department sets up a basic website to provide information about itself. This stage is unidirectional i.e. information is provided from the Government side only. The objectives of this stage are:

- Providing relevant information about the Government department to its stakeholders

- Updating information regularly on the portal

- Visitors are able to find the information they are searching for on the Government portal

With the above objectives the following key performance indicators are identified:

- $\quad$ Bounce rate: It is the number of visits in which a person leaves the website from the landing page with- 
out browsing any further. High bounce rate shows that either visitors came to the website accidently or they were not able to find the relevant information they were searching for on the site.

- $\quad$ Site experience of each stakeholder: This KPI is crucial for the Government portals at this stage. All the stakeholders must be satisfied with the experience of the portal. This can be further divided into: depth of visit, number of visits and new visitors.

- Measure the distribution of content in each section of website and the percentage of Visits to each section.

Tools and methods that can be used at Information stage to measure the response are:

- Ask visitors: Instead of using an analytic tool it is better to ask the visitors about their experience with the Government portal. This can be done through surveys. $4 \mathrm{Q}$ from iPerceptions, available in 18 languages, is a free on-exit survey. If the government department does not want to use an external survey, it can build its own, ask questions, and analyze the data (Kaushik, 2009). Department doesn't need to show the survey to everyone who visits the portal. Segmenting a small percent of visitors can be done. Only 300 responses are required in a month to get a statistically significant sample of data, and 1,200 to do segmented analysis.

- Distribution of content: It is important to compare the content on each page of the Government portal with the number of visits. Therefore, measuring the distribution of content in each section of the Government portal and the percentage of visits to each section is required. With this it will be known what the citizens are looking for on the portal. Also, this data can be used at the time of prioritizing the next set up of web pages of the Government Portal.
Google Website Optimizer is a free web page testing tool that enables the organization to seamlessly run experiments on a portal's visitorscomparing their different versions of the same page (A/B testing) or elements within the page that is Multivariate testing Brian (2012). Government department can choose what parts of page it wants to test, from the headline to images to text, and run experiments to see what users respond best to. And with Google Website Optimizer being free, it could be the only A/B (a technical term for multiple versions of the site running at once) and Multivariate (MVT) or complex testing solution.

- $\quad$ Measure bounce rate of the portal: It is usually measured in two ways: 1) The percentage of website visitors who see just one page on the portal; and 2) The percentage of website visitors who stay on the portal for a small amount of time (usually five seconds or less). There are two exceptions: The Government department has a single page portal and offline value proposition is so compelling that people would see just one single webpage and get all the information they need and leave. Google Analytics is helpful in estimating bounce rate. But it is important to keep in mind that search engines are sending large chunk of traffic. In order to find out the quality of traffic coming from the search engines ClickTracks report notices that each key word / key phrase performs differently, and it also differs by search engine.

- Depth of visit: Measured as the ratio of page viewed to visits, depth of visits is a measurement of interest in the content provided by the website. Larger numbers indicate more interest in the content provided.

- Visits/visitor: The ratio of visits to unique visitors is another good measurement of interest. This measurement is visitor-centric in 
nature. While depth of visits is reflective of the level of interest to site content, this indicator is a reflection of the portal's success at bringing stakeholders back to the site. The new visitor percentage is the ratio of new visitors to unique visitors and immediately assesses the effectiveness of the site in acquiring new visitors. If the Government portal is in new visitor acquisition mode, then a high ratio is desirable.

\section{Stage II: Interaction}

According to Sandoval-Almazan et al. (2010), this stage involves online form submission, queries and correspondence, etc. It is "interaction between the citizen and the Government": At this stage, the user is able to download forms, send emails to the concerned authority, ask query etc. (Alhomod et al, 2012; Almazan and GilGarcia, 2008; Cisco, 2007; Siau and Long, 2005; Chandler and Emanuel, 2002; Kim and Grant, 2010). For Gartner group (2001), this stage features tools for interaction with stakeholders like search engines along with documents downloading and emails. Web forms, help and frequently asked questions (FAQs) are also part of this stage (Windley, 2002). The primary objective of this stage is successful two-way communications which can be further divided into the following objectives:

- Citizens are able to successfully download forms, guides, applications from Government portals. For example: downloading forms from tender.gov.in and Income Tax department portal.

- $\quad$ Citizens can send emails, give feedback, ask queries etc. within the Government portal. Frequently asked questions (FAQ) section can be made available for citizens.

- Search option within the portal is given so that citizens can find relevant information within the Government portal.
- $\quad$ After completing the downloaded form from the portal, the citizens are able to submit the forms successfully online. Taking the same example as above, uploading Income Tax Return at www.incometaxindiaefiling.gov.in.

With these objectives the following key performance indicators are identified:

- $\quad$ Measure downloads: There are tons of downloads (pdf's mostly) like forms, applications, useful guides every day from Government portals. Tracking these downloads is essential.

- Voice of citizens: Knowing how, when and how many visitors contact the Government department via email, contact forms, live chat etc is extremely important.

- $\quad$ Statistics about live visitors: This KPI is useful for the Government portals that provide live chat rooms, $\mathrm{Q} /$ A sessions etc.

- $\quad$ Portal Search: understand what visitors are looking for, and what they are having trouble finding.

Analytic tools and methods that can be used at interaction stage are:

- Tracking downloads: It is crucial to track how many times citizens download particular files like Income Tax Return forms and application forms as these act as micro conversions. By using Google Tag Manager (GTM), the number of clicks on downloads can be monitored. It will allow keeping track of the number of times users download different types of files from Government portal. Every time a citizen clicks on a link that contains file extensions defined by an organization (example .pdf) an event will be recorded that is labelled with the type of the file and the URL of the file. It can then easily see in Google Analytics how many pdfs for example were 
downloaded from the portal and which ones.

- Voice of citizens' tools: It will be incorrect to believe that by just analyzing the clicks of visitors to the portal that "voice of citizens" can be captured. Surveys play a vital role here. Kissinsights from Kiss Metrics (kissinsights.com) and $4 Q$ by iPerceptions are one of the most widely used tools. Kissinsights requires Javascript installation which is easy to implement. It gives a customized feedback form for the visitors. All of the questions that are asked to the customers can be managed through a single and simple dashboard. The best part is that citizens or any other visitor's feedback comes in via very simplified and short comments.

- $\quad$ Stats about live visitors: Woopra is an easy to use tool that offers realtime analytics about live visitors. It builds behavioral profile for every visitor. Apart from page views and visitor's location, it gives the option of custom data that the organization can customize according to their goals. In addition, it provides the facility of chatting live with individual site visitors. It also tracks anonymous website \& mobile app users from their first touch.

- $\quad$ Site Search: Goggle analytics allows seeing what people search the Government portal for. This can help in understanding what visitors are looking for, and what they are having trouble finding. It is important to estimate site search usage i.e. how many visitors use the site search. Most of the bounce rate can come from unsatisfactory search results. Not only is the number of visitors who searched the portal important, the keyword they typed is equally important as well. This way the Government department will know what exactly the visitors are looking for in the portal

\section{Stage III: Transaction}

Stakeholders such as citizens, business and other Government departments are able to make transactions at this level of Government portal (Layne and Lee, 2001; Penalopez, 2012; Alhomod et al. 2012). According to Almazan and Gil-Garcia (2008) and Shahkooh et al. (2008), this stage has to be very secured as payment and citizens' vital information is being shared online. This way citizens' trust can be won. Keeping these definitions in mind, the following objectives can be identified:

- $\quad$ Citizens are able to register themselves securely and save their data (personal information, payment details etc.).

- $\quad$ Task completion rate: The citizens that enter the portal for transaction are able to complete the task easily and on time.

- $\quad$ Citizens' conversion rate: For Government organizations, the conversion rate is not measured with sales but here the primary objective is that the citizens not only search for information and interact online but also the same citizens are able to complete the transactions online. Still in India, most of the citizens use Government portals for gathering information. It is huge task to convert these information searching citizens into making payment online.

With these objectives the following key performance indicators are identified:

- $\quad$ Tracking registered citizens: Understanding the behavior of the citizens that have registered themselves on portal.

- $\quad$ Task completion rate: the number of citizens that are able to complete the transaction successfully. This KPI involves data about complete as well as incomplete tasks.

- Conversion rate: details of the citizens that were converted from in- 
formation surfing to completing transaction.

Analytic tools and methods that can be used at stage III are:

- Tracking registered users: For the Government portals that require log in, a web analytics tool like Google Analytics can track exactly what they did during each visit to the portal. This can allow for more detailed analyses and understanding of what different types of visitors are doing on Government portals that have achieved transaction level.

- Task Completion Rate: This KPI can be split into different variables.

The user defined is a variable that helps in defining specific types of users that have completed a goal or a specific action in the portal.

Bounce Rate \& Time on Site are two extremely useful variables which indicate whether citizens find what they are looking for in the portal or if they leave immediately. These metrics can be found in the visitor's section of Google Analytics, nevertheless it is also very useful to focus on them while evaluating the various channels/sources of traffic.

- $\quad$ Tracking incomplete transactions is a must. If the stakeholders start the process of transaction and abandon it before completing, then it is essential to find the root cause and solve the issue. Funnels help in tracing the path to a goal.

- Conversion rate: Conversion rate is the percentage of visits that result in the visitor taking an action that have been defined as important to an organization. Every portal is created with a pre-defined goal. For Government portals at Transaction level, the conversion rate is when the citizen completes a transaction online. For example: citizens paying donations online, payment of passport form fee online etc. Conversion rate is an effective KPI that helps to monitor the goals of the website. A high conversion rate indicates that considerable amount of visitors act according to the portal. To manage a high conversion rate, a portal should have the perfect mix of quality web traffic and an excellently managed visitor experience. The conversion rate KPI extracts the best value of such good measures. Google Analytics provides enormous stats of all the factors that affect the conversion rate. By listening to the voice of citizens, conversion rate will improve.

Conversion rate per medium shows the conversion rate of each medium and it is extremely useful to monitor it in order to distinguish the top selling channels.

The variable 'visits to purchase' i.e. how many visits does it take for a citizen to initiate and then complete a transaction online. This information is crucial in India where citizens are encouraged to use e-government services. Therefore, this will help in planning the content strategy for the portal. Even the information on 'time to purchase' i.e. how long does it take for the citizen to complete a transaction is critical. Longer the duration for completing a task online, more will be the chances of citizens avoiding it. Hence, the process of completing a transaction must be reduced to minimum and easy steps for citizens.

\section{Stage IV: Integration}

According to Hiller and Belanger (2001), Moon (2002), Chandler and Emanuel (2002) at integration level all the services are connected where all the data are shared within the same department and between different Governments departments. For this a powerful backend is required. Performance can be measured at this stage using statistical techniques (Kim and Grant, 2010). The performance of back end can be sub divided into different objectives. Also, for measuring the performance of back end need not necessarily require Web analytic tools. Keeping the enormous data both structured and unstructured in mind, big data tools become essential in 
handling integrated data of government. Following objectives can be identified:

- $\quad$ One of the primary objectives of this stage is to give a unified view to the citizens through Government portal.

- $\quad$ Back end integration of data: whether it is vertical or horizontal integration i.e. integration within the department or between departments, data become exponentially large. Hence, handling and organizing this data becomes an important task.

- Optimized back end in terms of technology and quality of service for handling load on Government portal if traffic increases. The portal of Indian railways (www.irctc.co.in) is an Indian example. During tatkal reservation (Tatkal booking is for immediate plans and the booking for every train opens two days in advance) when the number of visitors' increases and try to purchase the ticket online, the portal at times gets slow, hangs or the server goes down and therefore visitors are not able to complete the task. Because of which the citizens get frustrated and also lose interest in the portal.

- Understanding pattern, profile and behavior of all stakeholders using Government portal.

With the above objectives, the following key performance indicators can help in the analysis:

- As identified for stage I, the two KPIs: Bounce rate and site experience of the visitor remain the same for this stage as well. The reason being a visitor still wants all the information to be easily available and well distributed. And at this stage the visitor wants a unified view. For example, in case of passport application, citizens would like to see an integrated status of their passport in terms of police verification and application process on the same portal.
- Traffic Distribution by Country/Territory and time will help in understanding the peak time of visitors trying to transact or interact online so that special attention can be paid at the back end.

- Visitors' information (personal, payment options etc): This objective is a must for this stage to understand the online behavior of the citizen and build a relationship with the citizen.

Web analytic tools and methods suggested for Stage IV include:

- Hadoop: HDFS, the Hadoop Distributed File System, is a distributed file system designed to hold very large amounts of data (terabytes or even petabytes), and provide highthroughput access to this information. Files are stored in a redundant fashion across multiple machines to ensure their durability to failure and high availability to very parallel applications (Danny et al. 2015).

Big data analytics refers to Data analysis being undertaken that uses high volume of data from a variety of sources including structured, semi structured, unstructured or even incomplete data and the phenomenon whereby the size (volume) of the data sets within the data analysis and velocity with which they need to be analyzed has outpaced the current abilities of standard business intelligence tools and methods of analysis. For e-government, a huge amount of data is generated that needs to be stored and processed, a tool like Hadoop will be very useful.

- $\quad$ OpenRefine (formerly GoogleRefine) is an open source tool that is dedicated to cleaning and transforming data (Verborgh and Wilde, 203). It is a user friendly tool. Such tools will help in organizing the integrated data of Government portal. 
- $\quad$ Google Analytics console: Visualizing visitors' paths can be known from users flow report. User Flow Report is a graphical representation of the paths citizens have taken through Government portal, from the source, through the various pages, and where along their paths they exited the portal. It also compares volumes of traffic from different sources, examines traffic patterns through portal, and troubleshoots the efficacy of the portal (www.support.google.com/analytic).

- Customer Relationship Management (CRM) for Government portal data: CRM tools such as Oracle, Siebel; SalesForce etc help in building stronger relationships with stakeholders. A tailor made CRM on cloud can give Government a comprehensive view of useful data. Integrating the citizen's database i.e. where all the information (personal, payment options etc.) with web analytic tool is very critical. This will help in getting the surfing patterns of citizens and their behavior on the Government portal. By continuous analysis, Government department can work towards the improvement of the portal.

\section{Synthesis}

This section summarizes the objectives, key performance indicators and relevant web analytic tools for each stage of egovernment maturity model (Table 1). It can be seen that all the stages of maturity model have different objectives to achieve. Hence, all these objectives need to be handled differently. The key performance indicators at every stage change according to the objectives. KPIs in some cases have been further divided into smaller variables so that in-depth insights can be found. For example, at transaction level where conversion rate is the KPI, it has been divided into variables such as conversion rate per medium and visits to purchase. Both these variables will give insights about the citizen's experience at transaction level.
Bounce rate is an important KPI and must be used at all stages of Government portals. It is very important to estimate how many citizens entered the portal accidently and left the page immediately. Moreover it is important to know how much time they spent on each page. With high bounce rate it can be analyzed that either citizens are not satisfied with the content on the portal or they are not fully utilizing Government services online and so relevant measures must be taken.

At integration level, back-end analysis is the outmost priority. Integrating back-end citizen's information and data warehouse of the Government portal with web analytic tools such as Google Analytics can give useful insights that can help in improving Government services being provided through portal. By the time any Government organization achieves integration level, the data becomes gigantic. For this, big data tools need to be applied for organizing the data and then analyzing it.

The web analytic tools that have been suggested are mostly open source and free. These tools are widely being used and have no compatibility issues. Google Analytics is one of the most widely spread web analytic tool and very simple to install. Moreover, the user training of Google Analytics is very simple.

\section{Conclusion}

This paper identifies the objectives of each stage of e-government maturity models that have been developed over the years. Through literature, e-government stages that are relevant in the Indian context have been shortlisted. With every objective, a key performance indicator has been distinguished. KPI is a measurable value that demonstrates how effectively a company is achieving key business objectives. Web analytic tools for respective KPIs have been suggested. The tools that have been suggested are widely used, mostly open source and free.

One of the limitations of this work is that the aspect of social media involvement has not been included. As a future work, com- 
bining Government portal and its social media presence can be analyzed. Moreover, in future a framework can be developed for Government organizations that can help them in analyzing the performance of Government portals at each level of maturity models.

\section{References}

1. Alhomod, S. M., Shafi, M. M., Kousarrizi, M. N., Seiti, F., Teshnehlab, M., Susanto, H., Batawi, Y. A. (2012) 'Best Practices in E government: A Review of Some Innovative Models Proposed in Different Countries', International Journal of Electrical \& Computer Sciences, 12(01), 1-6.

2. Andersen, K. V. and Henriksen, H. Z. (2006) 'E-government Maturity Models: Extension of the Layne and Lee model', Government Information Quarterly, 23(2), 236-248.

3. Bekavac, I. and Daniela, G. P. (2015) 'Web Analytics Tools and Web Metrics Tools: An Overview and Comparative Analysis', Croatian Operational Research Review, 6(2), 373-386.

4. Chaffey, Dave, and Mark Patron. (2012) 'From Web Analytics to Digital Marketing Optimization: Increasing the Commercial Value of Digital Analytics', Journal of Direct, Data and Digital Marketing Practice, 14(1), 30-45.

5. Chen, J., Yan, Y. and Mingins, C. (2011) 'A three-dimensional model for e-government development with cases in China's regional e-government practice and experience Proceedings of Fifth International Conference on Management of e-Commerce and eGovernment (ICMeCG), 113-120

6. Clifton, B. (2012) Advanced web metrics with Google Analytics, John Wiley \& Sons.

7. Danny, P., Aditi, D., Sweety, P., Ashwini, N. and Supriya, S. (2015) 'Implementing Egovernance Using Hadoop', International Journal of Advance Foundation And Research In Science \& Engineering, 1 (Special Issue)
8. Fath-Allah, A., Cheikhi, L., Al-Qutaish, R.E. and Idri, A. (2014) 'e-Government Maturity Models: A Comparative Study', International Journal of Software Engineering \& Applications, 5(3), 71.

9. Hiller, J. and Be'langer, F. (2001) 'Privacy Strategies for Electronic Government', E-government, 200, 162-198.

10.Kim, D. Y. and Grant, G. (2010) 'Egovernment Maturity Model using the Capability Maturity Model Integration', Journal of Systems and Information Technology, 12(3), 230-244.

11.Layne, K. and Lee, J. (2001) 'Developing Fully Functional e-Government: A Four Stage Model', Government Information Quarterly, 18, 122-136.

12.Moon, M. J. (2002) 'The Evolution of eGovernment Among Municipalities: Rhetoric or Reality?', Public Administration Review, 62(4), 424-433.

13. Ronaghan, S. A. (2001) 'Benchmarking E-Government: A Global Perspective', United Nations Division for Public Economics and Public Administration and American Society for Public Administration.

14.Schuppan, T. (2009) 'E-Government in developing countries: experiences from sub-Saharan Africa', Government Information Quarterly, 26(1), 118-127.

15.Shahkooh, K. A., Saghafi, F., and Abdollahi, A. (2008) 'A Proposed Model for eGovernment Maturity', Proceedings of $3^{\text {rd }}$ International Conference on Information and Communication Technolgies: From Theory to Applications, 1-5.

16.Siau, K. and Long, Y. (2005) 'Synthesizing e-Government Stage Models - A Metasynthesis based on Meta Ethnography Approach', Industrial Management \& Data Systems, 105(4), 443-458.

17.Tripathi, R. and Gupta, M. P. (2014) 'Evolution of government portals in India: mapping over stage models', Journal of Enterprise Information Management, 27(4), 449-474. 
18.Peña-López, I. (2012) 'UN eGovernment Survey 2012', e-Government for the People [Online], [Retrieved March 2016],

http://unpan1.un.org/intradoc/groups/pu blic/documents/

19.Verborgh, R. and De Wilde, M. (2013) Using OpenRefine, Packt Publishing Ltd.
20.Waisberg, D. and Kaushik, A. (2009), 'Web Analytics 2.0: Empowering Customer Centricity', The original Search Engine Marketing Journal, 2(1), 5-11.

21.Web Analytics Association (2008) Web analytics definitions, Digital Analytics Association.

Table 1: Web Analytics for each Stageof e-Government

\begin{tabular}{|c|c|c|c|}
\hline Stage & Objectives of each Stage & Key Performance Indicators & Web Analytic Tool \\
\hline $\begin{array}{l}\text { Stage I: Infor- } \\
\text { mation }\end{array}$ & $\begin{array}{l}\text { - Providing relevant information } \\
\text { - Updating information regularly } \\
\text { - Visitors are able to find the infor- } \\
\text { mation }\end{array}$ & $\begin{array}{l}\text { - Bounce rate } \\
\text { - Site experience of each stake- } \\
\text { holder } \\
\text { - Distribution of content }\end{array}$ & $\begin{array}{l}\text { - } \quad 4 Q \text { from iPerceptions } \\
\text { - } \quad \text { Google Website Optimizer } \\
\text { - } \quad \text { Google Analytics } \\
\text { ClickTracks }\end{array}$ \\
\hline $\begin{array}{l}\text { Stage II: Interac- } \\
\text { tion }\end{array}$ & 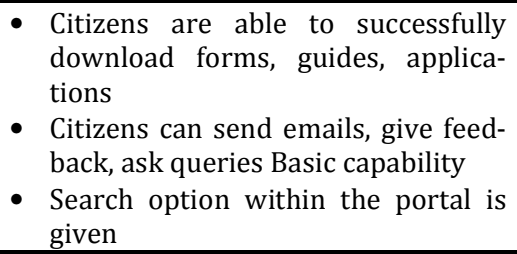 & $\begin{array}{l}\text { - } \quad \text { Measure downloads } \\
\text { - } \quad \text { Soice of citizens } \\
\text { - } \quad \text { Portalistics about live visitors }\end{array}$ & $\begin{array}{ll}\text { - } & \text { Google Tag Manager } \\
\text { - } & \text { Google Analytics } \\
\text { - } & \text { Kissinsights } \\
\text { - } & 4 \text { Q by iPerceptions } \\
\text { - } & \text { Woopra }\end{array}$ \\
\hline $\begin{array}{l}\text { Stage III: Trans- } \\
\text { action }\end{array}$ & $\begin{array}{l}\text { - } \text { Citizens are able to register } \\
\text { - Citizens are able to complete the } \\
\text { task easily } \\
\text { - Citizens conversion rate }\end{array}$ & $\begin{array}{l}\text { - } \text { Tracking registered citizens } \\
\text { - Task completion rate } \\
\text { - Conversion rate } \\
\text { - } \text { Bounce Rate }\end{array}$ & - Google Analytics \\
\hline $\begin{array}{l}\text { Stage IV: Integra- } \\
\text { tion }\end{array}$ & $\begin{array}{l}\text { - To transfer the existing process in a } \\
\text { bid to provide more efficient, inte- } \\
\text { grated, unified and personalized } \\
\text { services. } \\
\text { - Vertical and horizontal integration }\end{array}$ & $\begin{array}{l}\text { - Traffic Distribution by Coun- } \\
\text { try/Territory and time } \\
\text { - Integrating the citizen's database } \\
\text { with web analytic tool }\end{array}$ & $\begin{array}{ll}- & \text { Big data tools } \\
- & \text { Google Analytics console }\end{array}$ \\
\hline
\end{tabular}

